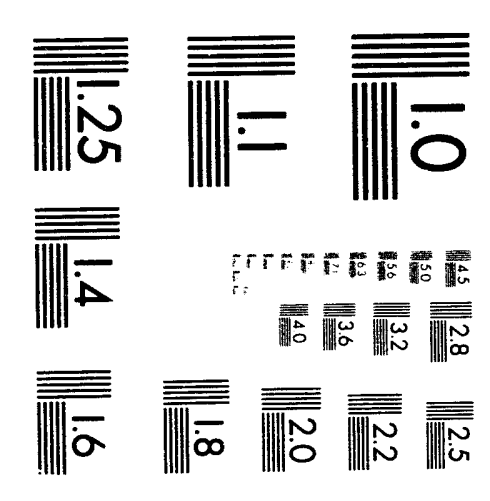



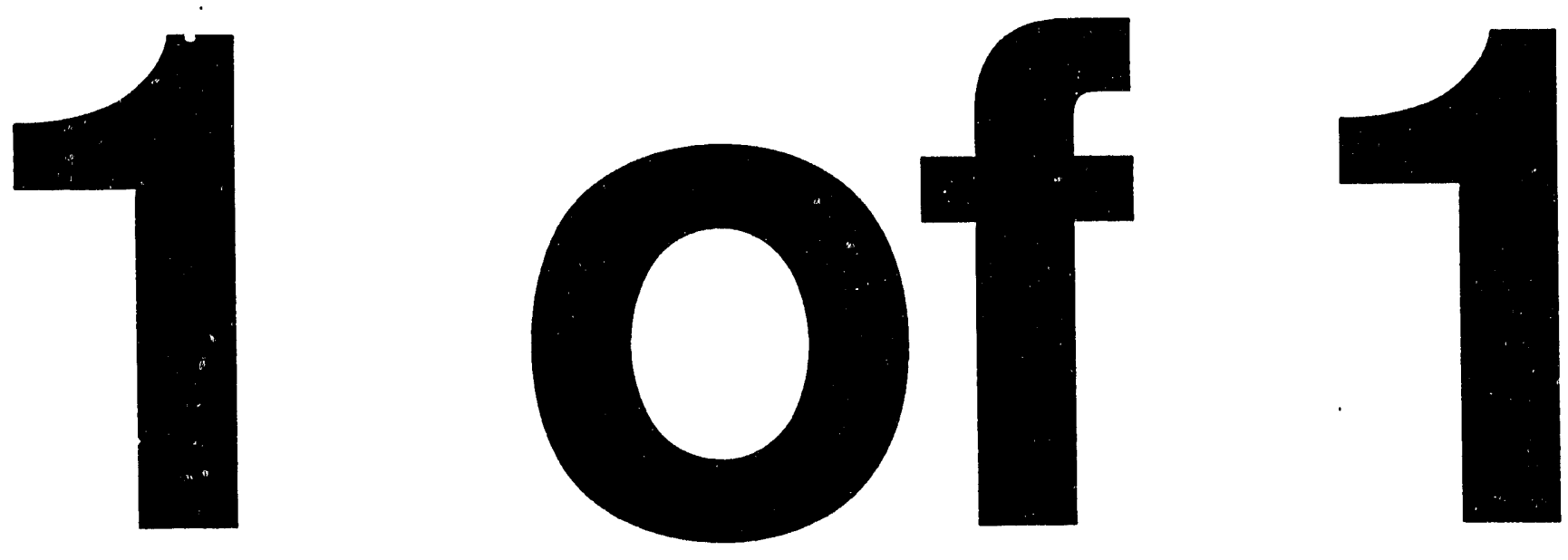


\title{
Users Manual for CATNIP: A Computer Analysis Tool for Normal Impact Penetration
}

\author{
Brad S. Altman \\ Advanced Munitions Department, 9723 \\ Sandia National Laboratories \\ Albuqueraue, New Mexico 87185
}

\begin{abstract}
This software is used to predict depth of penetration and time histories of depth, velocity, and acceleration of ogive-nose projectiles into various target materials. The predictions use projectile and target properties as inputs to the program. The program is based on analytical penetration models developed by Forrestal and co-workers using spherical cavity expansion approximations. The program has a graphical user interface which requires minimal time to learn and allows for simplicity while entering data.
\end{abstract}

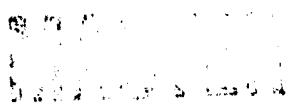




\section{Acknowledgement}

This work performaed at Sandia National Laboratories supported by the U.S. Department of Energy under contract DE-AC04-76DP00789. 


\section{Table of Contents}

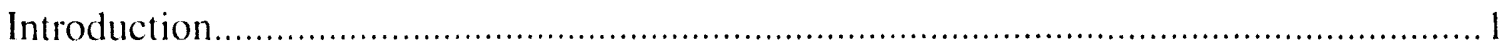

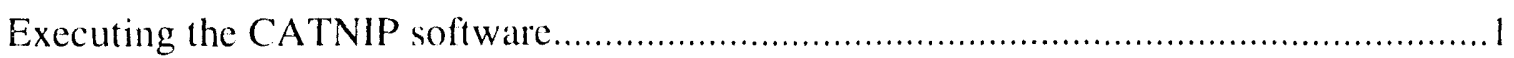

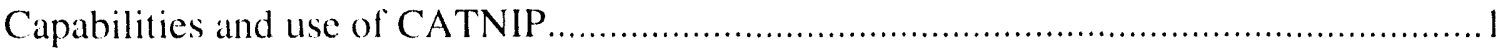

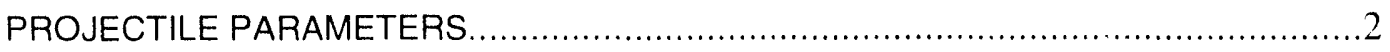

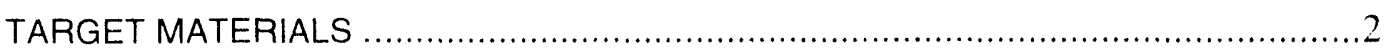

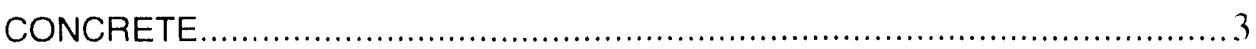

SOIL: Tresca yield criterion ..................................................... 4

SOIL: Mohr-Coulomb yield criterion...............................................

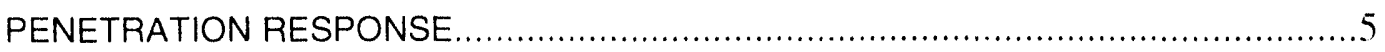

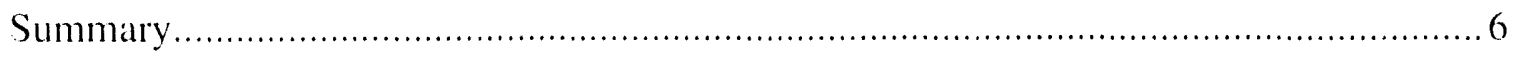

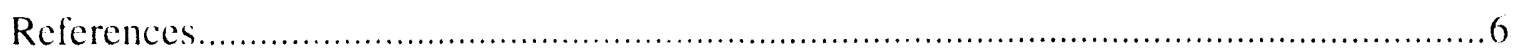

\section{List of Figures}

Figure 1. Control screen of CATNIP showing the 'graphical penetration equation'...........7

Figure 2. Projectile parameters input screen......................................................... 8

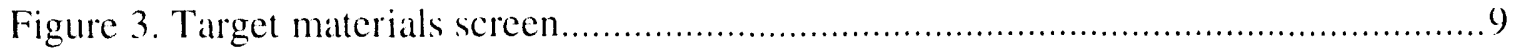

Figure 4. Concrete larget material parameters input screen..................................... 10

Figure 5. Soil target input screen using the Tresca yield criterion..............................11

Figure 6. Soil target input screen using the Mohr-Coulomb yield criterion.................... 12

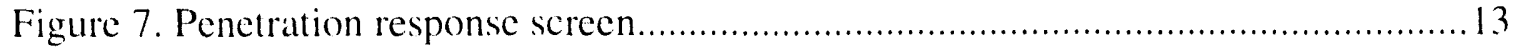

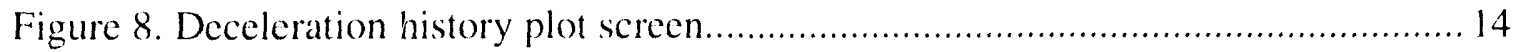

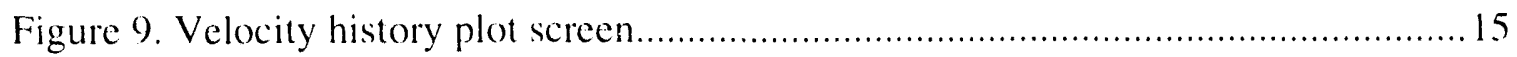

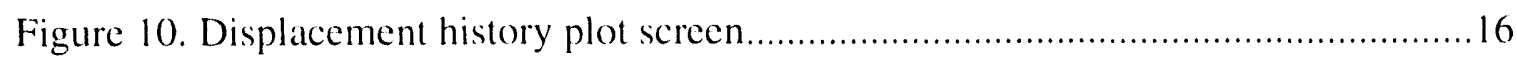




\section{Introduction}

This program was developed to provide a computer based framework for analytical models developed by Forrestal and co-workers [1-2] to predict depth of penetration and temporal quantities for rigid, nondeforming ogive-nose projectiles penetrating into a wide variety of targets. CATNIP provides results for penetration into semi-infinite targets, but does not provide for perforation events. The program has a graphical user interface to facilitate operation so that people unfamiliar with the analytical models can use the code with a minimum of training. CATNIP runs on Apple Macintosh computers using the Hypercard program. The Hypercard program is included with the system software on all Macintosh computers. A familiarity with the Macintosh use of fointing and clicking with the mouse is assumed for the use of this program.

\section{Executing the CATNIP software}

First install the Hypercard program onto the Macintosh's hard drive according to the instructions supplied with the software. Next install the CATNIP program onto the hard drive by dragging the CATNIP program icon from the floppy disk to the hard disk. The CATNIP program can be started in two ways: first, by double-clicking on the CATNIP icon on the hard disk; or second, start the Hypercard program by double-clicking on the Hypercard icon, choose Open from the File menu, click on the CATNIP name in the scroll box, and finally clicking the open button.

\section{Capabilities and use of CATNIP}

CATNIP uses a 'graphical penetration equation' shown in Figure 1. This equation states that the projectile parameters plus the target properties combine to give the necessary quantities for deep Penetration Response. Once the projectile and target parameters are input, the operator of CATNIP moves to the Penetration Response part of the program that calculates the depth and time of penetration as a function of striking velocity. Each of the three parts of the CATNIP penetration equation is a button. Clicking each specific button allows you to access each specific part of CATNIP. 


\section{PROJECTILE PARAMETERS.}

Clicking the PROJECTILE PARAMETERS button moves you to the PROJECTILE PARAMETERS screen (Figure 2). The input parameters for the projectile are: nose shape or caliber-radius-head (CRH), mass ( $\mathrm{kg}$ ), and shank diameter $(\mathrm{m})$.

nose shape: Figure 2 shows a schematic diagram of four different nose shapes or caliberradius heads of the projectile. The caliber-radius-head $\psi$ is defined by $\psi=\mathrm{R} / \mathrm{d}$ where $\mathrm{R}$ is the ogive radius and $d$ is the shank diameter. A nose shape is selected by placing the pointer over the desired icon and clicking the button. The nose shape is highlighted during this procedure to show that it has been selected. An option for variable caliberradius-head is used by clicking on the (UABIABite CBH button. Type the desired caliberradius-head. NOTE: this type of inpul box only requires that the desired number be input (no units), but hitting the return key is not required -- this convention will be followed throughout the CATNIP software program.

mass: The mass of the projectile is input by placing the cursor over the mass button and clicking once. Type the mass in kilograms $(\mathrm{kg})$ in the box with the flashing vertical bar cursor.

diameter: The shank diameter of the projectile is input by placing the cursor over the diameter button and clicking once. Type the diameter in meters $(m)$ in the box with the flashing vertical bar.

verify: Clicking the verify button displays the inputs and verifies that they are correct before continuation of the program. In addition to seeing the inputs, the nose shape coefficient $\mathrm{N}(\psi)=24 \psi^{2} /(8 \psi-1)$ is evaluated and displayed.

When the inputs on this screen are completed and the verify button has been clicked, click on the button to move back to the main CATNIP penetration equation screen.

\section{TARGET MATERIALS .}

Clicking the TARGET button moves you to the TARGET MATERIALS screen (Figure 3). This screen shows a list of the current target materials availabls. Placing the pointer on the desired target material title and clicking will take you to that materials parameter input screen. Currently 
there are three target materials available. One for concrete and two for soil. The soils are divided into two locking solid models, one for Tresca [1] and the other for Mohr-Coulomb [1] yield criteria.

\section{CONCRETE.}

The concrete material model used here is given by [2]. The model is based upon an empirical fit of concrete penetration data covering a wide varicty of projectile masses and target strengths. The parameters for this model are: unconfined compressive strength f'c, empirical parameter $S$, and density $\rho$. The Concrete target screen is shown in Figure 4.

unconfined compressive strength $f_{c}$ : The unconfined compressive strength of the concrete is input by placing the cursor over the $f^{\prime} c$ ] button and clicking once. Type the appropriate unconfined compressive strength in Pascals ( $\mathrm{Pa}$ ) in the box with the flashing vertical bar.

S parameter: The empirical parameter $S$ (no units) is input by placing the cursor over the $s$ Parameter button and clicking once. This button responds differently than the other buttons. When you click the button, CATNIP automatically calculates $\mathrm{S}$ according to the empirical model and puts it in the correct place. The calcualted $S$ paramter can be input manually by double-clicking in the $\mathrm{S}$ parameter value box and then typing the desired value for $\mathrm{S}$.

density : The density $\rho$ of the concrete is input by placing the cursor over the density button and clicking once. Type the density in kilograms per cubic meter $\left(\mathrm{kg} / \mathrm{m}^{3}\right)$ in the box with the flashing vertical bar.

model reference: Clicking the Model Reference button gives a reference for more detailed explanation the material model.

When the inputs on this screen are completed, click on the $\boldsymbol{a}^{\mathrm{s}}$ button to move back to the main CATNIP penetration equation screen. 
SOIL: Tresca yield criterion.

The soil material models used here are given by [1]. The soil target screen that uses the Tresca yield criterion is shown in Figure 5. The parameters for this model are: 'locked' value of volumetric strain $\eta^{*}$, shear strength $\tau_{0}$, Young's modulus $E$, and density $\rho$.

volumetric strain $\eta *$ : The locked volumetric strain value for the soil is input by placing the cursor uver the icon of $\eta^{*}$ on the $p-\eta$ graph and clicking once. Type the locked value of volumetric strain (no units) in the box with the flashing vertical bar.

shear strength: The shear strength $\tau_{0}$ of the soil is input by placing the cursor over the icon of $\tau_{\mathrm{O}}$ on the $\tau_{\mathrm{O}^{-}}$p graph and clicking once. Type the shear strength in Pascals (Pa) in the box with the flashing vertical bar.

Young's modulus: The Young's modulus E of the soil is input by placing the cursor over the Young's modulus button and clicking once. Type the Young's modulus in Pascals $(\mathrm{Pa})$ in the box with the flashing vertical bar.

density: The density $\rho$ of the soil is input by placing the cursor over the density button and clicking once. Type the density in kilograms per cubic meter $\left(\mathrm{kg} / \mathrm{m}^{3}\right)$ in the box with the flashing vertical bar.

model reference: Clicking the Model Reference button gives a reference for more detailed explanation the material model.

When the inputs on this screen are completed, click on the button to move back to the main CATNIP penetration equation screen.

\section{SOIL: Mohr-Coulomb yield criterion.}

The soil target screen that uses the Mohr-Coulomb yield criterion is shown in Figure 6. The parameters for this model are: 'locked' value of volumetric strain $\eta^{*}$, pressure dependent shear strength defined by $\tau_{0}$ and $\lambda$, Young's modulus $E$, and density $\rho$. The additional parameter $\lambda$ describes the slope of the $\tau$-p curve. All of the inputs act identically to those described in the Soil: Tresca yield criterion section and the input of the pressure dependent parameter $\lambda$ is described below. 
pressure dependent parameter: The pressure dependent parameter $\lambda$ of the soil is input by placing the cursor over the icon $\lambda$ on the $\tau$-p graph and clicking once. Type the locked value of volumetric strain (no units) in the box with the flashing vertical bar.

When the inputs on this screen are completed, click on the button to move back to the main CATNIP penetration equation screen.

\section{PENETRATION RESPONSE.}

Clicking the PENETRATION RESPONSE button moves you to the penetration response screen (Figure 7). This is the section of the program where predictions of penetration depth as a function of striking velocity and coefficient of sliding friction are made This screen has two inputs: striking velocity and coefficient of sliding friction. The outputs or results are the time and depth of penetration. In addition there are a buttons to generate history plots of the temporal quantities.

striking velocity: The striking velocity is input by placing the cursor over the STAIKING UELOCITY button and clicking once. Type the striking velocity in meters per second $(\mathrm{m} / \mathrm{s})$ in the box with the flashing vertical bar.

friction: The coefficient of sliding friction is input by placing the cursor over the FRICTION button and clicking once. Type the coefficient of sliding friction (no units) in the box with the flashing vertical bar.

penetration response: Clicking the PENETARTION RESPONSE button gives the results of the CATNIP program for the specific penetration event. The results are total time of penetration in $\mathrm{ms}$ (the time elapsed from striking the target until the projectile comes to rest), the depth of penetration in $m$ (the depth from striking the target surface to the nose of the projectile), and the maximum deceleration in $\mathrm{g}$ 's and the time at maximum deceleration .

deceleration history plot: Clicking the OECELERATION HISTORY PLOT button moves to the deceleration plot screen (Figure 8). A deceleration-time plot for the current penetration event is displayed A button labeled PRINT GRAPH is included on this card. Ciicking this button will print the graph on the current printer. Click on the button to move back to the PENETRATION RESPONSE screen. 
velocity history plot: Clicking the UELOCITY HISTORY PLOT button moves to the velocity plot screen (Figure 9). A velocity-time plot for the current penetration event is displayed. A button labeled PRINT GRAPH is included on this card. Clicking this button will print the graph on the current printer. Click on the at button to move back to the PENETRATION RESPONSE screen.

displacement history plot: Clicking the (OISPLACEMENT HISTORY PLOT) button moves to the displacement plot screen (Figure 10). A displacement-time plot for the current penetration event is displayed. A button labeled PRINT GRAPH is included on this card. Clicking this button will print the graph on the current printer. Click on the button to move back to the PENETRATION RESPONSE screen.

When finished with this screen, click on the button to move back to the main CATNIP penetration equation screen. Note that at any time it is possible to return to any screen, change parameters, and return to the PENETRATION RESPONSE screen for further penetration response calculations.

\section{Summary}

This document comprises a users manual for CATNIP: A Computer Analysis tool for Normal Impact Penetration. The features of the program are documented, but the reader is referred lo the cited references for in-depth investigation of the penetration and material models.

\section{References}

11) M. J. Forrestal and V. K. Luk, "Penetration Into Soil Targets", International Journal of Impact Engineering, V 12, No. 3, pp427-444, 1992.

[2] M. J. Forrestal, B. S. Altman, J. D. Cargile, and S. J. Hanchak, "An Empirical Equation for Penetration Depth of Ogive-nose Projectiles into Concrete Targets", to appear in the International Journal of Impact Engineering, 1993. 
Computer

A nalysis

J'ool for

Normal

Ilmpact

Penetration
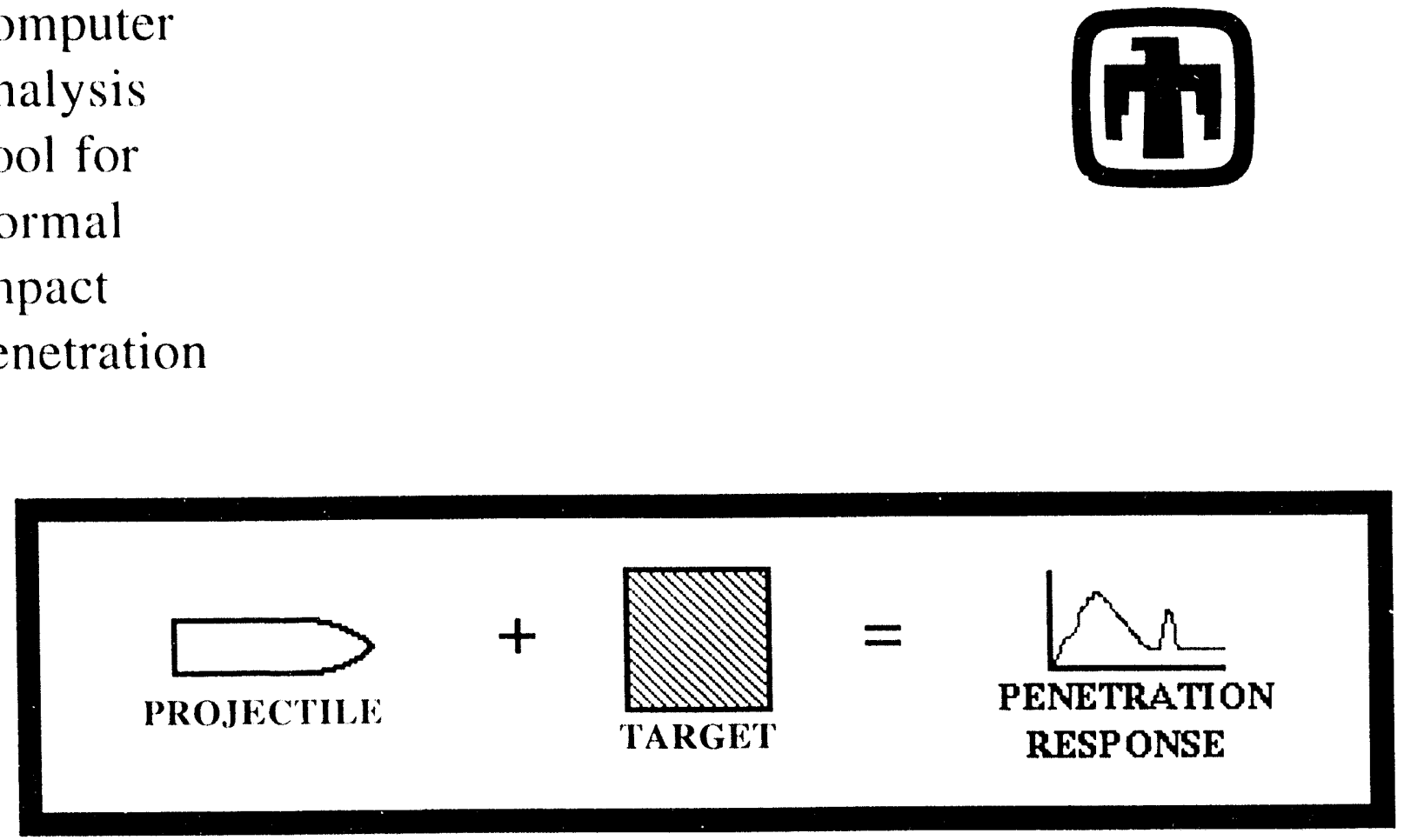

Figure 1. Control screen of CATNIP showing the 'graphical penetration equation'. 


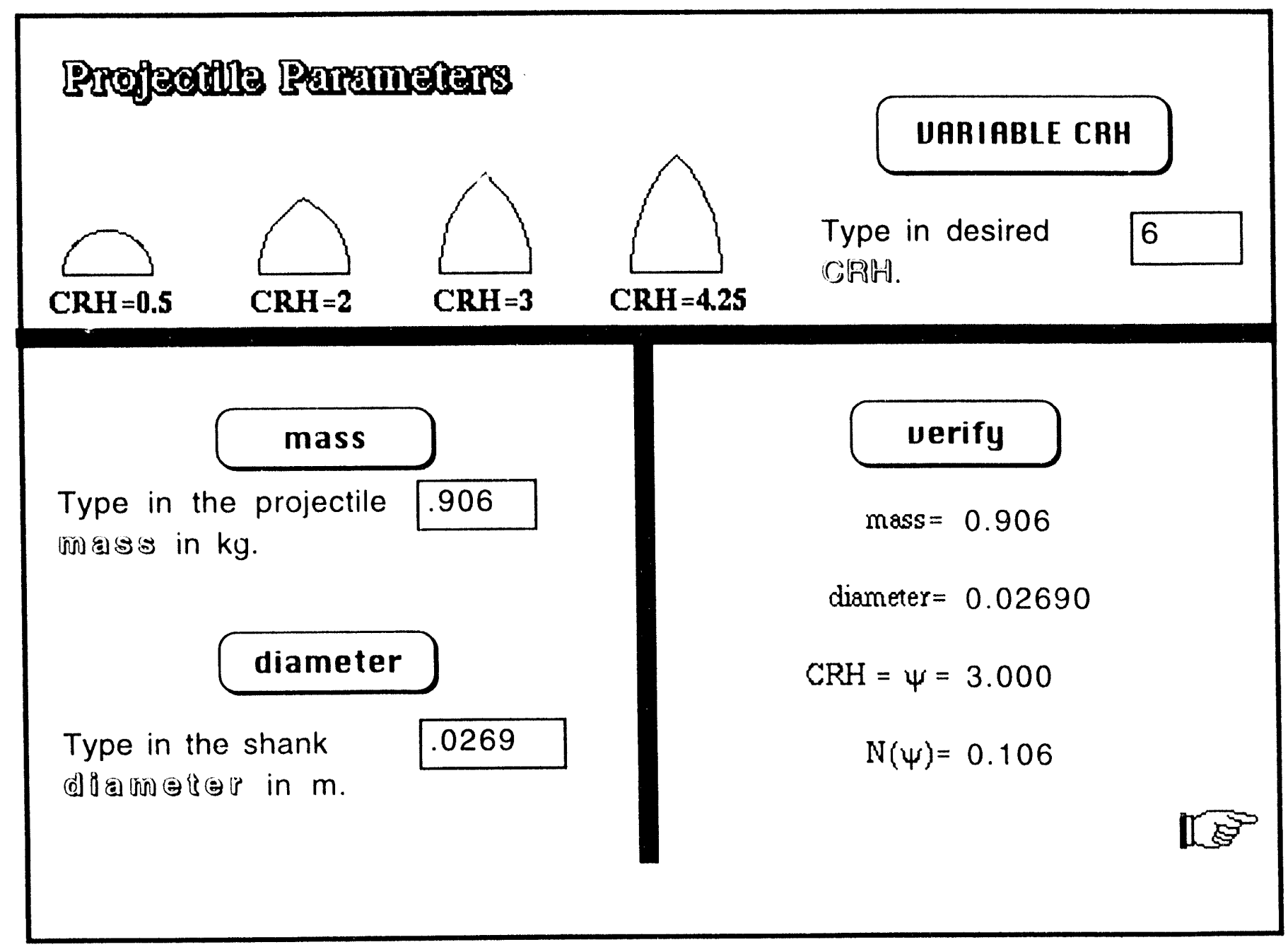

Figure 2. Projectile parameters input screen. 
?

\section{Choose the M"gurget Mlaterial}

CONCRETE : NEW IRIMIPIIBICALL EQUATION

SOIL : ELASTIC ITIRISSCA PLASTIC with CRATER PHASE

SOIL : ELASTIC MIOBIB_COULOMIB PLASTIC with CRATER PHASE

4

5

6

7

ज

Figure 3. Target materials screen. 


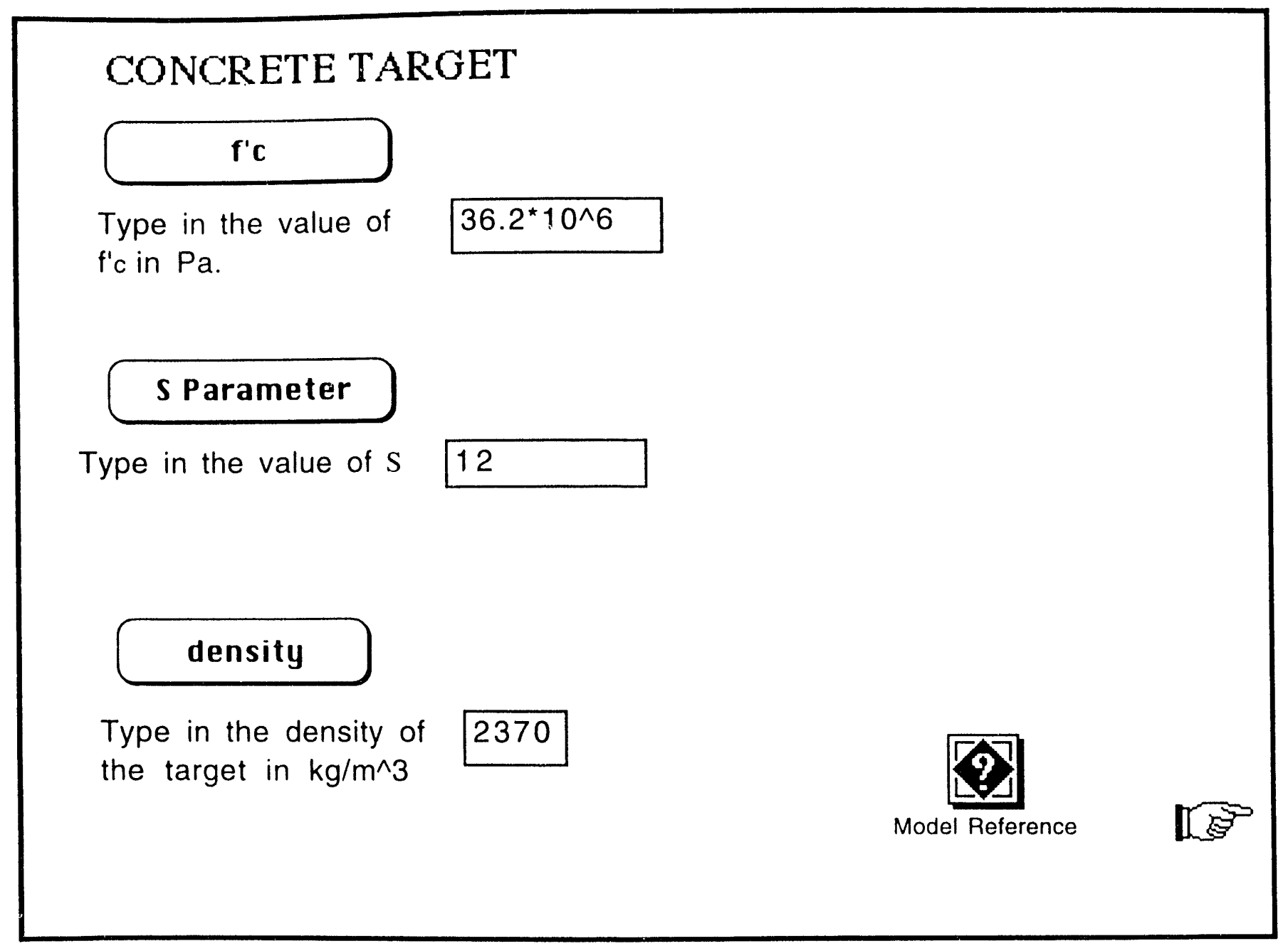

Figure 4. Concrete target material parameters input screen. 


\section{SOIL TARGET:}

- Locking Solid

$\mathrm{p}$

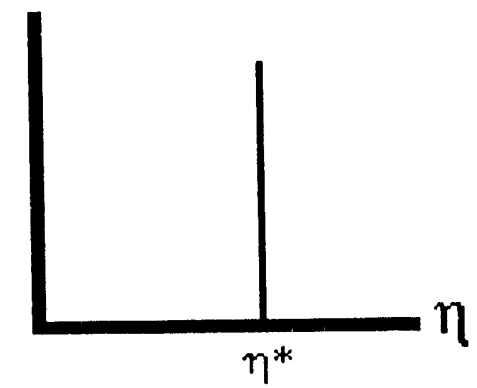

Type in the value $\eta^{*}$
- Tresca Criterion

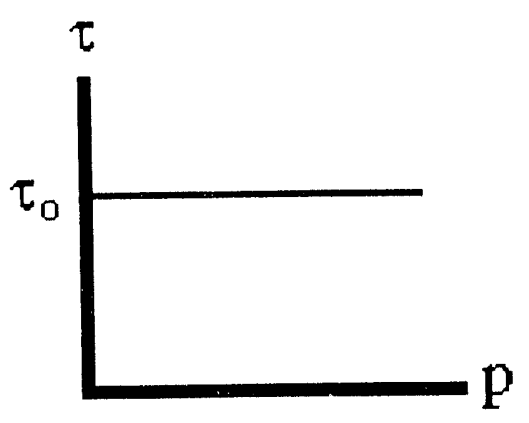

Type in the value of $\tau_{o}$ in $\mathrm{Pa}$.

\section{Young's modulus}

Type in the value of $\mathrm{E} 160^{\star} 10^{\wedge} 6$ in $\mathrm{Pa}$.

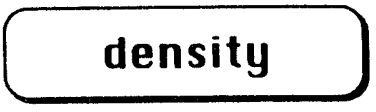

Type in the density of 1860 the target in $\mathrm{kg} / \mathrm{m}^{\wedge} 3$

Figure 5. Soil target input screen using the Tresca yield criterion. 


\section{SOIL TARGET:}

- Locking Solid

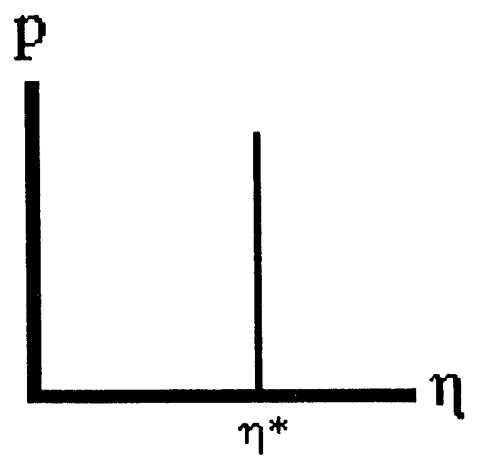

Type in the value $\eta^{*}$

.1

Young's modulus

Type in the value of $E 100000$

- Mohr-Coulomb Criterion Model Explanation

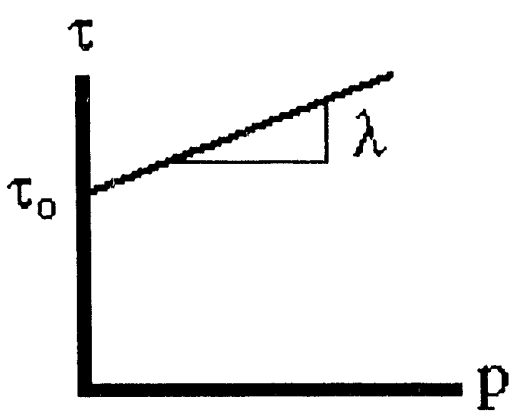

Type in the value of

5000

$\tau_{0}$ in $\mathrm{Pa}$.

Type in the value of $\lambda 500$ in $\mathrm{Pa}$.

Type in the density of 1750

the target in $\mathrm{kg} / \mathrm{m}^{\wedge} 3$

Figure 6. Soil target input screen using the Mohr-Coulomb yield criterion. 


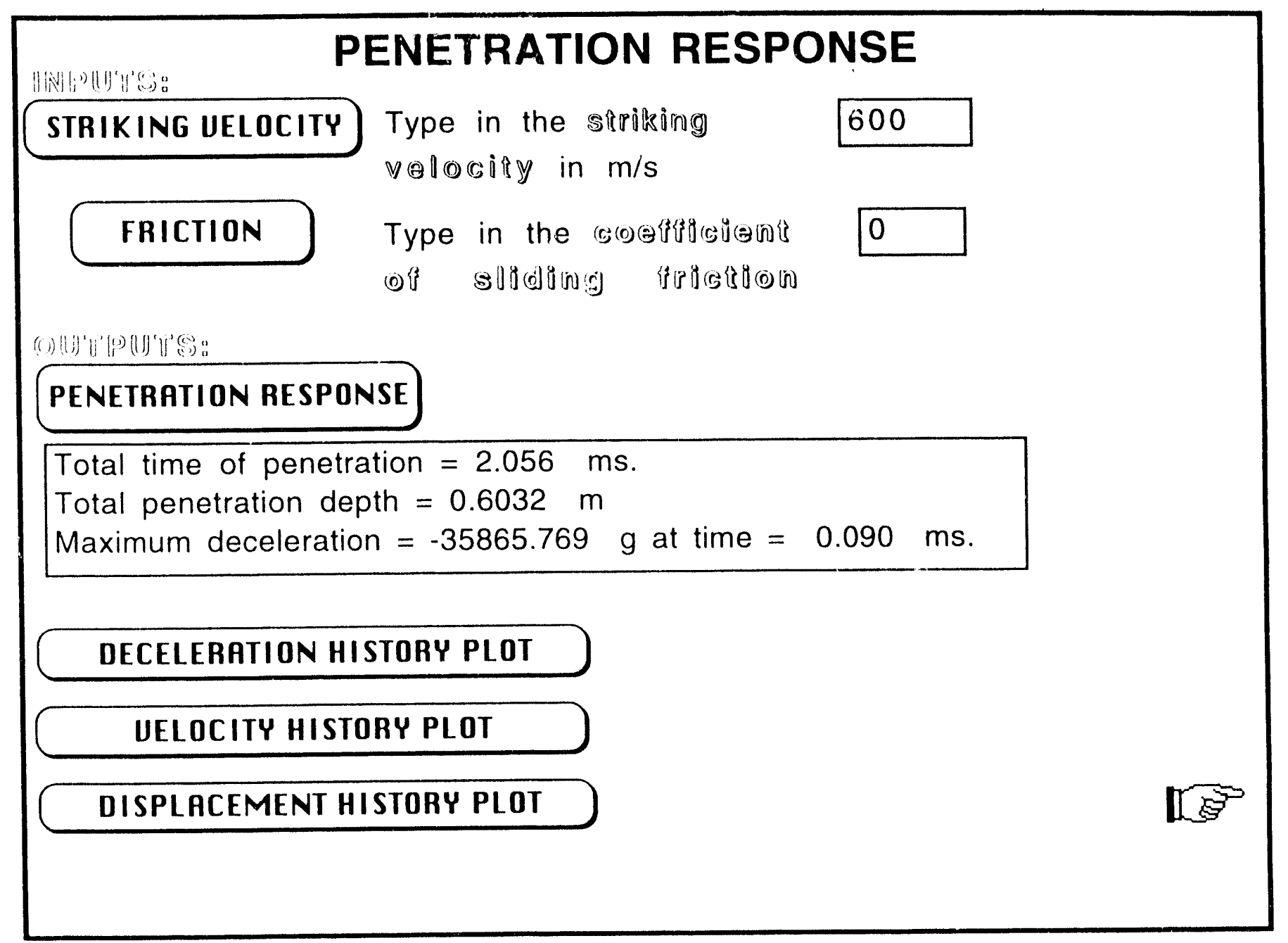

Figure 7. Penetration respcnse screen. 


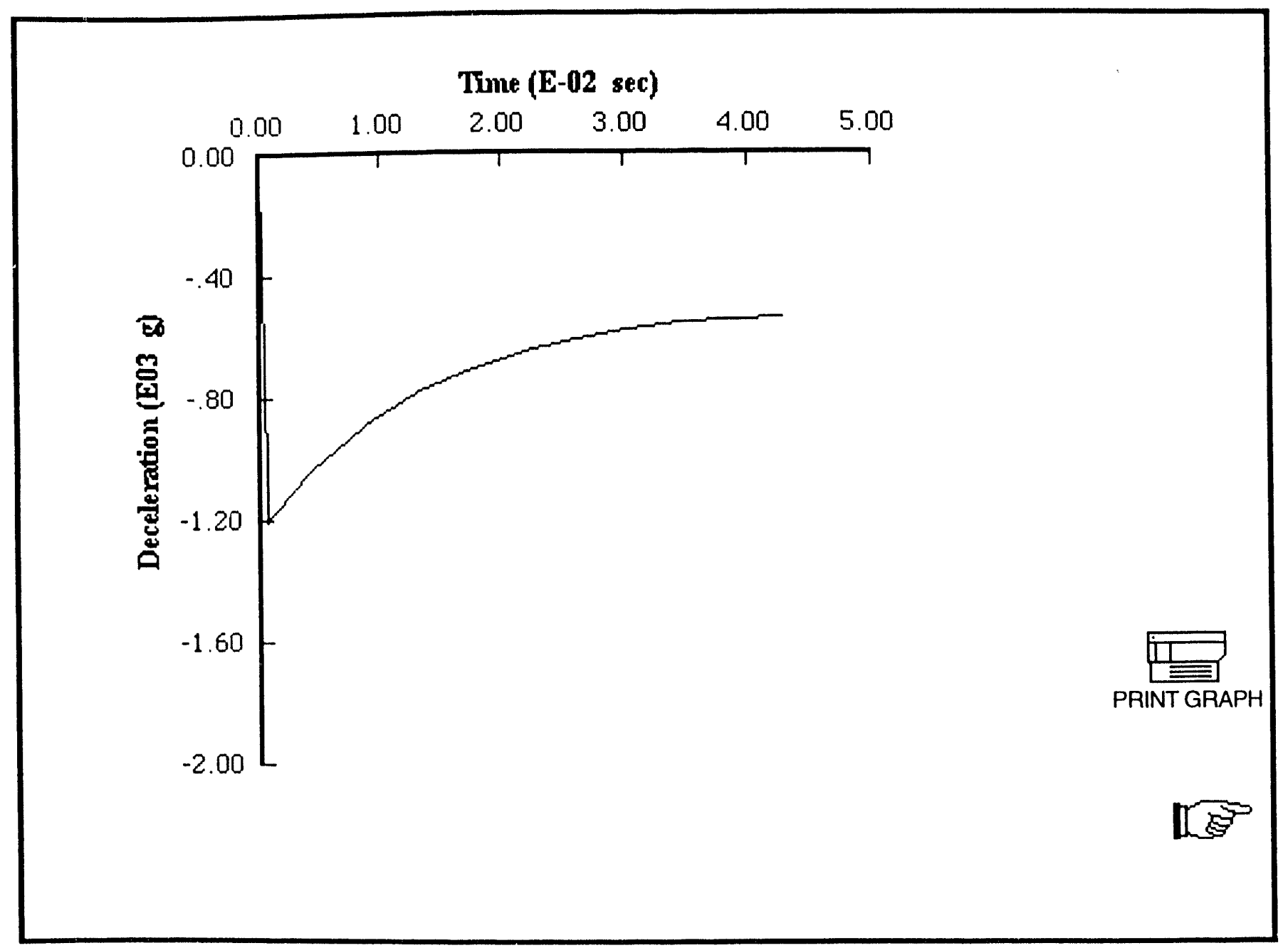

Figure 8. Deceleration history plot screen. 


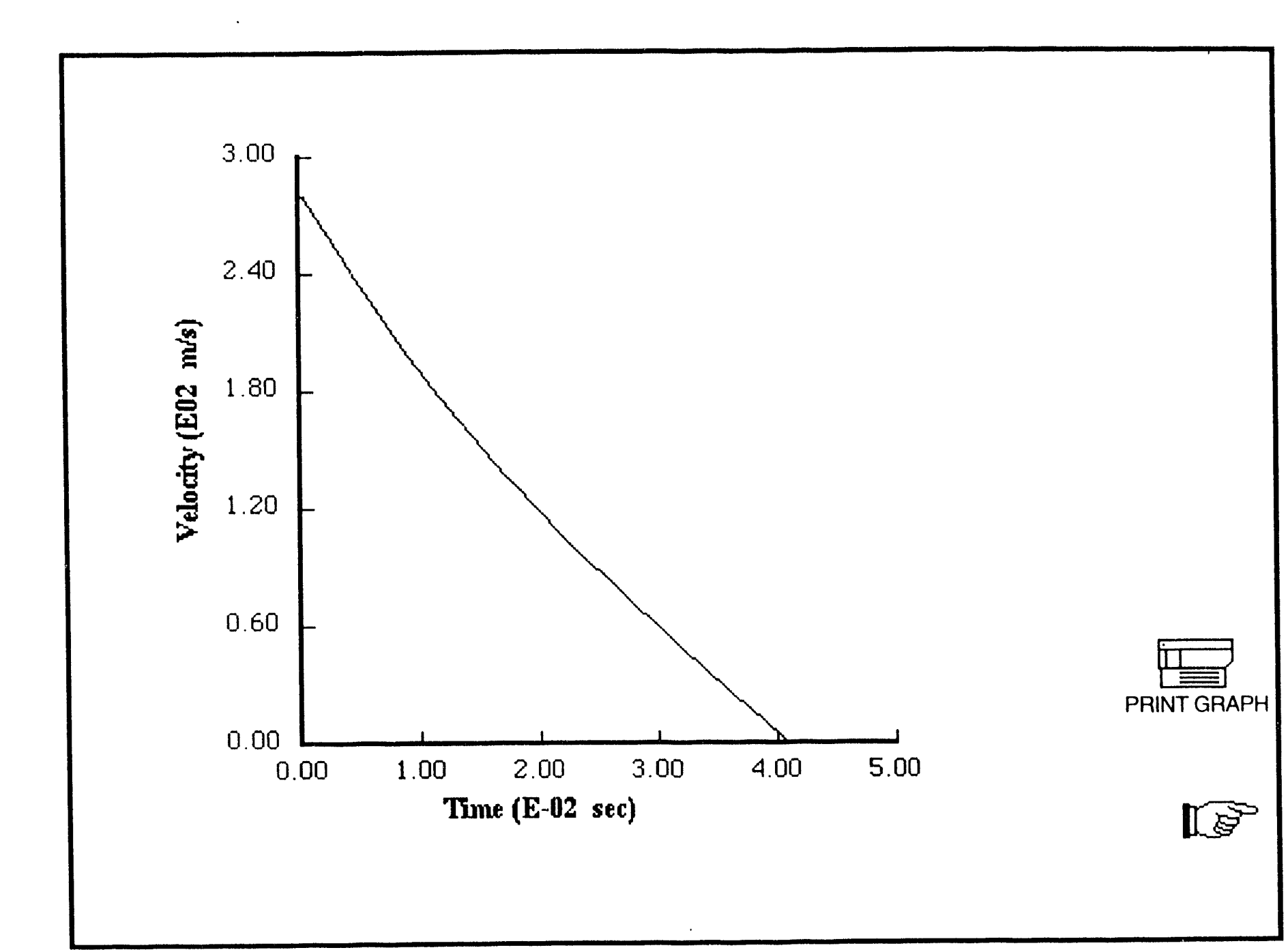

Figure 9. Velocity history plot screen. 


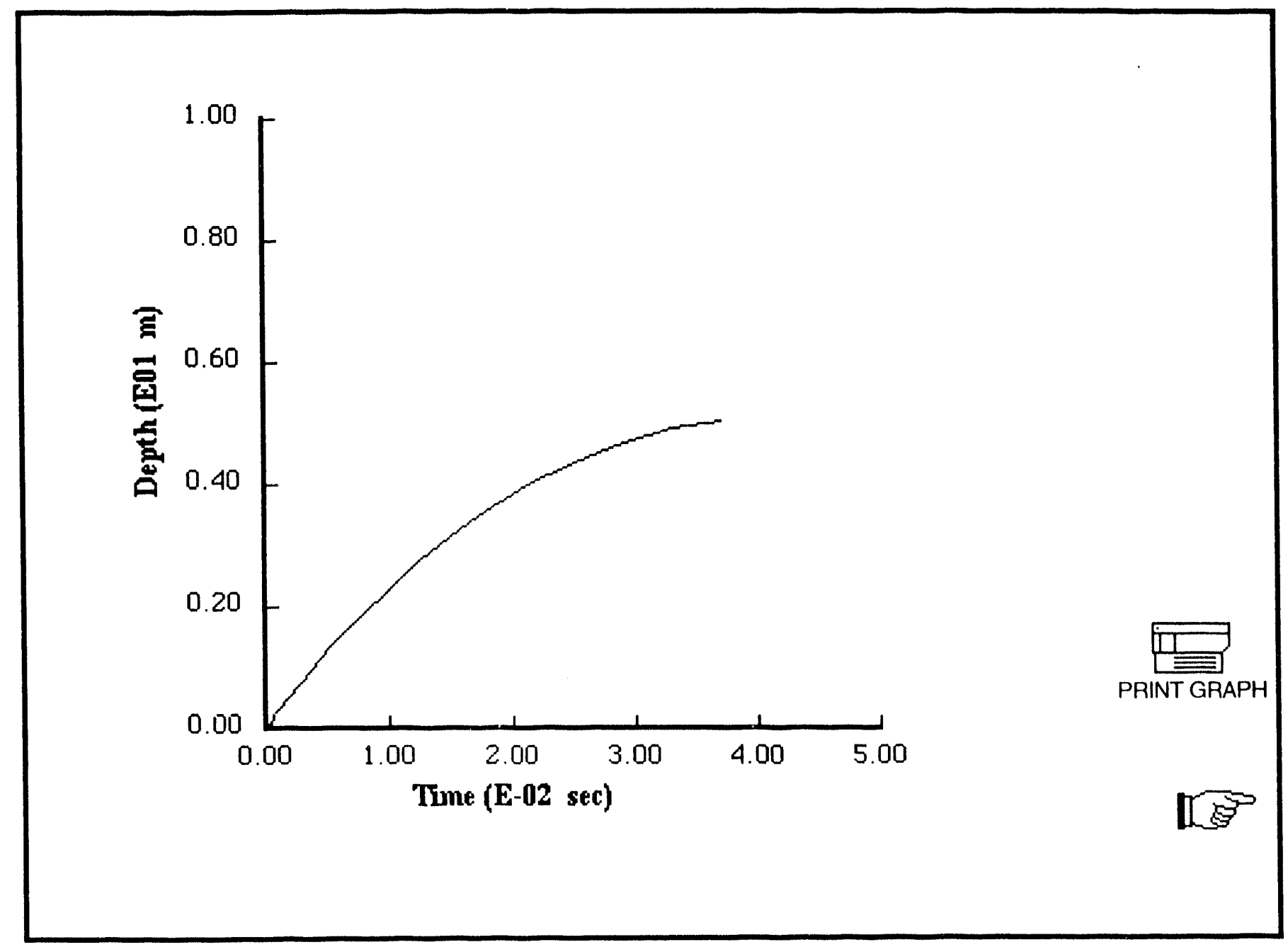

Figure 10. Displacement history plot screen. 


\section{Distribution List}

Alliant Techsystems Inc.

Attn: Dr. Gordon Johnson

MN 11-2925

600 2nd St NE

Hopkins, MN 55343

California Research and Technology

Attn: Y. M. Ito

20943 Devonshire St.

Chatsworth, CA 91311

Logicon/RDA

Attn: Ed Humphreys

6940 S. Kings Hwy, Ste 210

Alexandria, VA 22310

FC/DNA

Attn: Doug Seemann

FCTP

Kirtland AFB, NM 87115-5000

Naval Surface Warfare Center

Dahlgren Division

Attn: Walter Hoye, Code G22 (2 copies)

Dahlgren, VA 22448-5000

Waterways Experiement Station

Attn: CEWES-SD-R/Dr. Bob Rohani (4 copies)

P.O. Box 631

Vicksburg, MS 39180

Armament Directorate

Attn: John Collins (3 copies)

WL/MNMW

101 W. Eglin Blvd, Ste 337

Eglin AFB, FL 32542-6810

Defense Nuclear Agency

Attn: Joseph Renick

FCDNA/FCTP

Kirtland AFB, NM 87117

Director

Defense Nuclear Agency

Attn: SPSD/Mr. Mike Giltrude

6801 Telegraph Road

Alexandria, VA 22310-3398 
Armament Directorate

Attn: Dick Mabry (3 copies)

WL/MNMW

101 W. Eglin Blvd, Ste 219

Eglin AFB, FL 32542-6810

UDRI

Attn: S. N. Brar

Impact Physics Laboratory

Dayton, OH 45469

Calif. Inst. of Tech.

Attn: Tom Ahrens

Graduate Aeronautical Laboratories

Pasadena, CA 91125

University of Denver Research Institute

Attn: James Kellar

2050 East Iliff Ave

BW-228

Denver, CO 80208

Applied Research Associates

Attn: Frank Maestas

4300 San Mateo Blvd.

Suite A-220

Albuquerque, NM 87110

Sandia National Labs

Attn: Mike Ferrario

P.O. Box 969, Dept 5375

Livermore, CA 94550

1432 S. A. Silling

1433 D. E. Grady

1434 D. B. Longcope

1562 R. K. Thomas

1562 E. P. Chen

1562 E. D. Reedy

2664 D. E. Ryerson

5165 N. R. Hansen

6117 W. A. Olsson

6411 B. S. Altman (10 copies)

7141 Technical Library (5 copies)

7151 Technical Publications

7613-2 Document Processing for DOE/OSTI ( 10 copies)

8523-2 Central Technical Files

9701 J. P. Hickerson (2 copies)

9702 W. K. Tucker

9723 J. Holovka

9723 M. J. Forrestal (5 copies)

9723 R. G. Lundgren

9723 V. K. Luk

9727 B. J. Gomez 

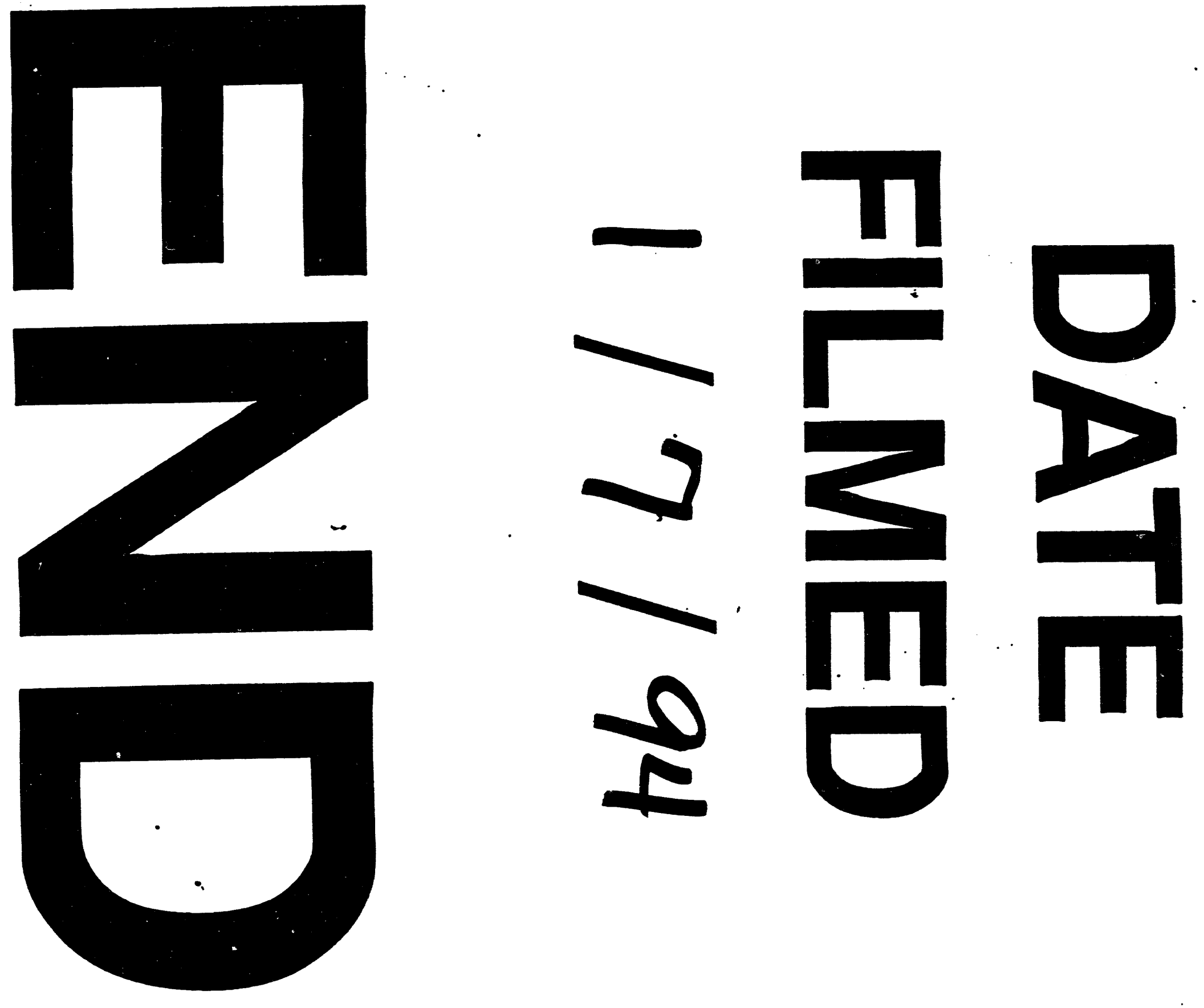
